\title{
Optimism, Hope, and Happiness as correlates of Psychological Well-Being among Young Adult Assamese Males and Females.
}

\author{
*NazirulHasnain, **SyedaWasfeeaWazid,*** ZubyHasan \\ *Professor, Departmentof Psychology, JamiaMilliaIslamia, New Delhi, India. \\ **Research Scholar, Departmentof Psychology, JamiaMilliaIslamia, New Delhi, India. \\ *** Research Scholar, Departmentof Psychology, JamiaMillialslamia, New Delhi, India.
}

\begin{abstract}
The purpose of the present study was to ascertain the contribution of Optimism, Hope and Happiness in Psychological Well-Being of young adult Assamese males and females. It also investigated the difference between young adult Assamese males and females on Psychological Well-Being, Optimism, Hope and Happiness. For this purpose a sample of 100 young graduate adults, 50 males and 50 females, residing in the Kamrup district of the state of Assam was taken.Ryff scales of Psychological Well-Being ,Life Orientation Test of Scheier\& Carver for optimism, Adult Trait Hope Scale of Snyder and Oxford Happiness Questionnaire were used.Separate regression analyses were run to find out the percentage of variance contributed by Optimism, Hope and Happiness in Psychological Well-Being of males and females. In order to find out the difference between means of young adult Assamese males and females on different variables, t-test was applied. Significant combined contribution of variance of Optimism, Hope and Happiness in Psychological Well-Being of young adult Assamese males and females were obtained. However, only Hope in males and happiness in female individually contributed 63\% and 53\% significant variance respectively to their Psychological WellBeing. Significant difference between young adult Assamese males and females on Psychological Well-Being and happiness were obtained, where females were found to be higher on well being and males on happiness. Non-significant differences between young adult Assamese males and females on Optimism and Hope were obtained.
\end{abstract}

Key words: psychological well-being, optimism, hope, happiness

\section{Introduction}

Psychological well-being is important with respect to how we function and adapt and with respect to whether our lives are satisfying and productive. Psychological well-being refers to how people evaluate their lives. According to Diener and Suh (1997), these evaluations may be in the form of cognitions or in the form of affect. The cognitive part is an information based appraisal of one's life that is when a person gives conscious evaluative judgments about one's satisfaction with life as a whole. The affective part is a hedonic evaluation guided by emotions and feelings such as frequency with which people experience pleasant/unpleasant moods in reaction to their lives. According to Kitchener and Jorm (2002a),Psychological well-being can be described as a state of mind with an absence of a mental disorder, from the perspective of positive psychology, it may include an individual's ability to enjoy life, and create a balance between life activities and efforts to achieve psychological resilience. Snyder and Lopez (2007) correctly proposed the formula: Happiness + Meaning = Well-being. Diener $(1984,2000)$ used the terms happiness and subjective well-being interchangeably, reflecting a hedonic perspective of subjective well-being. A eudaimonic perspective of subjective well-being focuses on meaning and virtue (Waterman, 1993; Ryan \& Huta, 2009). An optimist is widely thought of as someone who sees the silver lining in every cloud and views the world through rose tinted spectacles (or a glass that is always half full). Scheier and Carver (1985) defined optimism as 'the global generalised tendency to believe that one will generally experience good versus bad outcomes in life'. Optimism is often defined as a disposition to expect the best and view events and situations in a positive light. In the context of resiliency, optimism refers to a sense of a positive future, to a tendency to find positive meaning in experiences, and a belief in one's ability to impact positively on one's environment and situation. Optimism may be beneficial in several ways. Firstly, optimism naturally promotes a more positive mood, which helps to ward off depression and anxiety. Secondly, optimism also encourages greater persistence in the face of obstacles, which in turn is likely to result in greater success. Finally, there is evidence that optimists actually look after their health better than pessimists. They are more likely to seek out information about potential health risks and change their behaviour to avoid those risks. Snyder (2002) defined hope, "as the perceived capacity to derive pathways to desired goals, and motivate one's self via agency thinking to use those pathways". It is overall perception that one's goals can be met. According to Snyder (2000), hope has three necessary ingredients: Goal-oriented thoughts, Pathways to achievement of those goals and agency thoughts directed to goal achievement. Snyder and colleagues have mentioned (Snyder, 
Cheavens, Micheal, 1999), hope is a motivational concept but clearly has a strong cognitive component. Hence including this part of hope, they defined hope as "a reciprocally derived sense of successful agency (goaldirected determination) and pathways (planning of ways to meet the goals)" (Snyder et al., 1991). Hope has been found to be associated with (a) higher competency in academics (Snyder et al., 1997), (b) use of adaptive coping methods, (Irving, Snyder \& Crowson, 1998), (c) more flexible and positive thoughts (Snyder et al., 1996; McCullough \& Snyder, 2000), and (d) more positive appraisals of stressful events (Affleck \& Tennen, 1996). Hope has been taken as an individual difference factor that colors one's appraisal of stressors and the coping process (Snyder et al., 1991). Thus, individuals high in hope should appraise stressors as more challenging (as opposed to more threatening), and thus have the ability and motivation to find solutions to ameliorate the stressful feelings and resolve the stressor as a function of this orientation (consistent with the transactional model of stress and coping; Lazarus \& Folkman, 1984; Thompson, Gustafson, Hamlett, \& Spock, 1992).

Being happy is of great importance to most people, and happiness has been found to be a highly valued goal in most societies (Diener, 2000). Happiness, in the form of joy, appears in every typology of "basic" human emotions. Feeling happy is fundamental to human experience, and most people are at least mildly happy much of the time (Diener \& Diener, 1996). Philosophers and social researchers have defined happiness in a variety of ways (Kesebir \& Diener, 2008). The largest divide is between hedonic views of happiness as pleasant feelings and favourable judgements versus eudaimonic views of happiness involving doing what is virtuous, morally right, true to oneself, meaningful and/or growth producing (Ryan \& Desi, 2001; Ryff \& Singer, 2008). Altson and Dudley (1987) proposed that happiness is the ability to enjoy one's experiences accompanied by degree of excitement. Argyle, Martin and Crossland (1989) believe that happiness is composed of three related components- positive affects, absence of negative affects and satisfaction with life as a whole. The successful pursuit of happiness is vital to our life satisfaction. All of us want to lead meaningful and fulfilling lives, want to enhance our experiences of love and relationship. Happiness is commonly defined as a state of well-being, it is commonly associated with feeling good or experiencing pleasures. It is an emotional or affective state that is characterised by feelings of enjoyment and satisfaction. As a state and a subject, it has been pursued and commented on excessively throughout world history. This reflects universal importance that humans place on happiness. Freud (1930/1961) has stated that there is no doubt that man sought happiness above all other goals in life. He defined happiness as criteria excellence in the art of living.

\section{Review of literature}

Park (2004) presented comprehensive perspectives on well-being that included positive aspects of human life such as subjective well-being. Life satisfaction is the cognitive component of subjective well-being and plays an important role in positive development as an indicator, a predictor, a mediator and an outcome. Whereas low life satisfaction is associated with psychological, social and behavioural problems, on the other hand high life-satisfaction is related to good adaptation and optimal mental health among youths. Life satisfaction and positive affect mitigate the negative effects of stressful life events and work against the development of psychological and behavioural problems among youths. Supportive parenting, engagement in challenging activities, positive life events and high quality interactions with significant others contribute to the development of life satisfaction.

Vitterso (2004) articulated an important difference between well-being and self-actualisation. Although self-actualisation reflects a substantial aspect of human existence, Vitterso argues that the concept is not accounted for by ordinary assessment of well-being. Openness to experience (OE) was taken as an indicator of self-actualisation and overall satisfaction of life, frequency of positive affect and frequency of negative affect were utilised as indicators of well-being. Two methods were offered to investigate the assumed independence of well-being and OE, both of which comprised questionnaire data from 264 students attending the Norwegian folk high school systems. First, a structural equation model revealed only a small and non-significant association between well-being and OE. Second, by means of a flow complex it was shown that well-being and OE relate to different dimensions of experience. Well-being was associated with pleasantness, while, OE correlated with interestingness and challenge. It was concluded that traditional measurements of well-being are insensitive to important aspects of human lives, and that the concept misses important aspects of psychological well-being.

Ryff (2005) reported that measures of psychological well-being have little theoretical grounding, despite an extensive literature on the contours of positive functioning. Aspects of well-being derived from the literature on self-acceptance, positive relations with others, autonomy, environmental mastery, purpose in life, and personal growth were operationalised. Three hundred and twenty-one men and women, divided among young, middleaged, and older adults, rated themselves on these measures along with six instruments prominent in earlier studies (i.e., affect balance, life satisfaction, self-esteem, morale, locus of control, depression). Results revealed that positive relations with others, autonomy, purpose in life, and personal growth were not strongly tied to prior assessment indexes. 
Baker (2005) examined relationships among three measures of subjective well-being (life satisfaction, happiness and depressive symptoms) and two global measures of productive activity (number of activities and time commitment). They argued that participation in multiple productive activities should increase subjective well-being because these behaviours increase social integration and provide meaningful social roles. The multivariate regression shows that as time committed to productive activities increases, life satisfaction increases. Both increasing numbers of productive activities and increasing time commitment predict higher levels of happiness. The results provided support for the idea that engaging in productive activities is beneficial to older persons' well-being.

Wellner and Adox (2000) have reported that an optimistic attitude or positive thinking is the key to success and happiness- and there is plenty of research to back the claim up. Studies have shown that positive thinking can reduce tension and enhance emotional well-being and cardiovascular health (Calabia, 2000). A study found that women who had a more optimistic outlook tended to be less worried about breast cancer, while pessimists had a tendency to overestimate their risk of being diagnosed with the disease. Not only are optimists shown to be more resilient in the face of difficulties, but they also have healthier lifestyle habits, and cope with stress more easily. Their proactive approach to life and ability to see the possible in the impossible also makes them quite successful.

Reivich and Shatte (2002) found that part of what enables people to thrive despite setback, failure, and hardship is the ability to think optimistically in the face of adversity. Optimistic thinking motivates peopleadults and children- to continue to persist and work to find solutions, even when situations look bleak. Optimism shines light where it is dark.

Optimism is also linked to life longevity. Maruta, Colligan, Malinchoc, and Offord (2000) examined whether explanatory styles served as risk factors for early death. With a large longitudinal sample collected in the mid-1960s, the researchers categorised medical patients as optimistic, mixed or pessimistic. Optimism was operationalised using parts of the Minnesota Multi-phasic Personality Inventory. The researchers found that for every 10 point increase in a person's score on their optimism scale, the risk of early death decreased by $19 \%$. Considering that, for a middle-aged person of average health, the difference between sudden death risk factors for smokers and non-smokers is $5-10 \%$, the protective effect of optimism found in this study was massive.

Nelson, Roberts, Snyder (2010) measured eighty-nine early adolescents for perceptions of hope, exposure to violence, and perceived vulnerability to victimization. Results showed the presence of high hope, together with a high degree of exposure to violence. The adolescents were about equally divided regarding the nature of their own death, while most predicted a violent death for the "average American." The highest levels of hope were reported by those who had witnessed violence but not experienced it personally; those with the greatest exposure to violence predicted their own death would be violent.

Ciarrochi, Heaven and Davies(2007)examined the distinctiveness of three "positive thinking" variables (self-esteem, trait hope, and positive attributional style) in predicting future high school grades, teacher-rated adjustment, and students' reports of their affective states. It was revealed that each positive thinking variable was distinctive in some contexts but not others. Hope was a predictor of positive affect and the best predictor of grades, negative attributional style was the best predictor of increases in hostility and fear, and low self-esteem was the best predictor of increases in sadness.

Valle, Huebner, and Suldo (2006) in a longitudinal study, involving middle and high school students, provided evidence of (1) stability of hope reports of adolescents over a 1-year period, (2) predictive validity of adolescent hope reports, and (3) hope's functional role as a moderator in the relationship between stressful life events and adolescent well-being. Taken together, the results provide support for consideration of hope as a key psychological strength in youth. The findings are consistent with theories of motivation in which individual differences in hopeful thinking are conceptualized to play a functional role in linking life events and psychological well being.

Adelabu (2008) examined the relationship of academic achievement to future time perspective (FTP), hope, and ethnic identity among low-income, rural and urban African American adolescents. Findings indicated that adolescents who are oriented toward the future, determined to reach their goals (hope), and interested in and have a strong sense of belonging to their ethnic group tend to academically outperform adolescents reporting lower scores in the areas of FTP, hope, and ethnic identity. Regression analyses indicate that FTP, hope, and ethnic identity explain a significant, independent portion of the variability in academic achievement. However, ethnic identity is a stronger predictor of academic achievement for urban than rural African American adolescents.

Moraitou, Kolovou, Papasozomenou and Paschoula (2006), examined the relationship between hope as disposition, adaptation to old age, and individual-demographic factors. Regression analyses showed that hope as pathways thought predicted all factors of adaptation i.e., "Health Comparison", "Self-Efficacy", "SelfControl", and "Generativity" whereas hope as agency thinking predicted only "General Adaptation/Self- 
Efficacy" and "Self-Control". There were also some effects of gender, education, marital status, place of residence, and health status on specific aspects of adaptation to old age.

Brodaty, Brodaty, Caunt and Franklin (2013) explored conceptions of the elements or ingredients that lead to long-lasting happiness. A content analysis coded 201 respondents' (18-84 years old) written happiness recipes for the mention of a priori (pre-defined from a literature review) and empirical (from a pilot study) content analysis categories. These were organized into six dimensions (i.e. Personality, Circumstances, Social Relationships, Behavioral Activities, Cognitive Activities and Volitional Activities). Participants were happy and mentally healthy. An overwhelming majority of responses referred to Social Relationships such as with Family, Friends and Partners, supporting the assertion that relationships are necessary for happiness.

Wang and Wong (2013) studied the statistical link between leisure and happiness. Using survey data from 33 countries in 2007, they found that (1) leisure's role in self-fulfillment and social interaction, and leisure's relation to work and other spheres of life are significantly linked to individual happiness; (2) the effect of leisure quantity is not as important as other aspects of leisure; and (3) some leisure activities can be negatively associated with happiness. Consistent with findings in previous studies, family income and individual demographic variables such as age and health condition were significantly associated with happiness. National unemployment and political stability also have robustly significant effects on happiness.

Páez, Sánchez and Seguel (2012) attempted to ascertain whether alexithymia, suppression and reappraisal coping, and humor styles account for incremental variance in happiness (Lyubomirsky's scale) and psychological well-being (Ryff's scale), after controlling for Big Five traits and emotional positivity ratio of previous day's mood. Results suggested that low suppression, low self-critical use of humor and affiliative humor are correlates of psychological well-being, whereas self-enhancing humor and low suppression are correlates of happiness, playing a mediational role between personality traits and well-being.

Kageyama (2012) tested the explanatory power of happiness on survival at the aggregate level. Based on previous findings that psychological stress adversely affects survival and that its effect on survival is more severe for men, this study uses the sex difference in, rather than the level of, life expectancy as the dependent variable. The study demonstrated that the life expectancy gap negatively affects national happiness. It also showed that happiness was significant in explaining the cross-country differences in the life expectancy gap. As national average happiness decreases, the sex difference in life expectancy increases. This result suggests that happiness has a significant impact on survival even at the aggregate level.

Perneger, Hudelson and Patrick (2004), explored whether self-reported happiness is associated with mental and physical health status among young Swiss adults. Results indicated a strong association between happiness and mental health. This suggests that asking people if they are happy may help identify mental health care needs. Thus, self-reported happiness may also be a useful outcome measure for evaluation of health interventions.

Keeping in view the important roles played by optimism, hope and happiness in well-being of individuals and gender differences in these variables, the present study was conducted on Assamese young adult males and females. It is important to note that Assamese people have a liberal view of gender differences.

\section{Method}

Participants

The participants of the present study consisted of 100 young adults. They included 50 males and 50 females of 20 to 22 years of age, residing in the Kamrup district of the state of Assam. The participants were taken on incidental basis from different educational institutions of Assam. All of them were graduates. Measures

The following measures were used to measure well-being, hope, optimism and happiness of the respondents.

The Ryff scales of Psychological Well-Being (Ryff, 1989): The short form of the Ryff inventory which consists of 18 questions was used. The inventory consists of a series of statements reflecting the six areas of psychological well-being: autonomy, environmental mastery, personal growth, positive relations with others, purpose in life, and self-acceptance. Respondents rate statements on a scale of 1 to 6 , with 1 indicating strong disagreement and 6 indicating strong agreement. Internal consistencies varied between 0.87 and 0.93 and testretest reliability coefficient ranged between 0.81 and 0.85 .

The Adult Trait Hope Scale (Snyder et al., 1991):The adult hope scale of Snyder et al. (1991) was used to measure the hope of the respondents. The scale contains 12 items. Four items measure pathways thinking, four items measure agency thinking, and four items are fillers. Participants respond to each item using a 8-point scale ranging from definitely false to definitely true and the scale takes only a few minutes to complete. In a study by Kermani, Khodapanahi, \& Heidari (2012), Cronbach's Alpha for the Hope Scale was found to be 0.86 and test-retest reliability was found to be 0.81 . 
The Life Orientation Test - Revised (LOT-R) (Scheier and Carver,1985):Scheier and Carver (1985) introduced their index of optimism, as including positive("I am always optimistic about my future") and negative ("I rarely count on good things happening to me") expectancies. The LOT-R has displayed acceptable internal consistency (alpha of 0.78 ) and its test-retest correlations are 0.68 to 0.79 for intervals of 4 to 28 months (Scheier and Carver, 1985).

The Oxford Happiness Questionnaire (OHQ, Hills \& Argyle, 2002): An improved instrument, the Oxford Happiness Questionnaire (OHQ), has been derived from the Oxford Happiness Inventory, (OHI). The OHI comprises 29 items, participants respond to each item using a 6-point scale ranging from strongly disagree to strongly agree. The OHQ demonstrates high scale reliabilities with values $(168)=0.91$. The inter-item correlations for the OHQ ranged from 0.04 to 0.65 , mean 0.28 .

\section{Results}

Mean and S.D. of scores on different scales were calculated. T-test was used to find out the difference between Optimism, Hope, Happiness and Psychological Well-Being scores of young adult Assamese males and females. Regression analysis was used to ascertain the contribution of variance of optimism, hope and happiness as predictor variables on well-being as criterion variables.

Table 1: Contribution of variance by optimism, hope and happiness in well-being of Assamese males.

\begin{tabular}{|l|c|c|c|}
\hline \multirow{2}{*}{ Variables } & $\begin{array}{c}\text { Standardized } \\
\text { Coefficients }\end{array}$ & \multirow{2}{*}{$\mathbf{t}$} & \multirow{2}{*}{ Sig. } \\
\cline { 2 - 2 } & Beta & $\mathbf{t}$ & \\
\hline & & & $>0.05$ \\
\hline Optimism & .103 & .839 & $<0.01$ \\
\hline Hope & .633 & 3.896 & $>0.05$ \\
\hline Happiness & -.001 & -.008 & \\
\hline
\end{tabular}

$R^{2}=0.440 ； F=12.063 ； p=.01$

Table 1 shows that a total of $44 \%$ variance in well-being among young adult Assamese males was contributed together by optimism, hope and happiness. To make it more meaningful individual contribution of each of the three predictors were found out with the help of standardized beta coefficients. The beta coefficient shows that out of three predictors only hope counted $63 \%$ variance. Thus, out of the three only Hope emerged as the significant predictor of Psychological Well-Being among males, which was significant at .01 level of significance.

TABLE 2: Contribution of variance by optimism, hope and happiness in well-being of Assamese females.

\begin{tabular}{|l|c|c|c|}
\hline \multirow{2}{*}{ Variables } & Standardized Coefficients & \multirow{2}{*}{ Sig. } \\
\cline { 2 - 3 } & Beta & t & Sig \\
\hline Optimism & & & \\
\hline Hope & -.169 & -1.271 & $>0.05$ \\
\hline Happiness & .110 & .797 & $>0.05$ \\
\hline
\end{tabular}

$\mathbf{R}^{2}=0.305 ; \quad F=6.732 ; p=.01$

Table 2 shows that a total of $30 \%$ variance in well-being among young adult Assamese females was contributed together by optimism, hope and happiness. To make it more meaningful individual contribution of each of the three predictors were worked out with the help of standardized beta coefficients. Out of the three predictors only Happiness emerged as the significant predictor of Psychological Well-Being among females and 53\% variance was contributed by happiness in the psychological well-being of Assamese females, which was significant at 0.01 level of significance.

TABLE 3: Difference between mean Optimism, Hope, Happiness and Psychological Well-Being scores of young adult Assamese males and females.

\begin{tabular}{|l|l|c|c|c|c|c|c|}
\hline Variables & Groups & N & Mean & Std. Deviation & Std. Error Mean & t & Sig. (2-tailed) \\
\hline \multirow{2}{*}{ PsyWB } & Males & 50 & 71.0800 & 10.12340 & 1.43167 & \multirow{2}{*}{3.786} & \multirow{2}{*}{$<0.01$} \\
\cline { 2 - 6 } & Females & 50 & 78.6600 & 9.89457 & 1.39930 & & \\
\hline Optimism & Males & 50 & 14.7400 & 3.53299 & .49964 & 0.119 & $>0.05$ \\
\hline
\end{tabular}


Optimism, Hope, and Happiness as correlates of Psychological Well-Being among Young Adult

\begin{tabular}{|l|l|c|c|c|c|c|c|}
\hline & Females & 50 & 14.8200 & 3.17959 & .44966 & & \\
\hline \multirow{2}{*}{ Hope } & Males & 50 & 43.8600 & 8.83640 & 1.24966 & \multirow{2}{*}{1.705} & \multirow{2}{*}{$>0.05$} \\
\cline { 2 - 6 } & Females & 50 & 46.5200 & 6.60315 & .93383 & & \multirow{2}{*}{2.400} \\
\hline \multirow{2}{*}{ Happiness } & Males & 50 & 17.38990 & 1.1914 & 2.45930 & $<0.01$ \\
\cline { 2 - 6 } & Females & 50 & 13.15715 & 1.2654 & 1.86070 & & \\
\hline
\end{tabular}

The above table shows that Mean of Psychological Well-Being scores of Young Adult Assamese males and females were 71.08 and 78.66 and their SD's were 10.12 and 9.89 respectively. The t-ratio between the means of the two groups was found to be 3.78 which was significant at 0.01 level of significance. Here females had greater mean than males. However, males had greater mean than females on happiness, had 17.38 and 13.15 means and their SDs were 1.19 and 1.26 respectively. The t-ratio between the means of the two groups was found to be 2.40 which was significant at 0.01 level of significance. Two other comparisons came out to be nonsignificant.

\section{Discussion}

Hope and Happiness together emerged as significant predictors of Psychological Well-Being among young adult Assamese males.

In a place where conflict is ongoing for many years, the males of the society have strength of expectations to provide adequate protection to women and children. The expectation to earn a good living and better socio-political environment, males gain their strength to make the constructive contribution to their family and society, is a good promoter of better well-being, it is hence agreeable that Hope contributed significantly towards Psychological Well-Being amongst the young Assamese males. Researchers found Hope to be associated with (a) higher competency in numerous life areas (e.g., academics; Snyder et al., 1997), (b) use of adaptive coping methods, (e.g., Irving, Snyder \& Crowson, 1998) (c) more flexible and positive thoughts (Snyder et al., 1996; Snyder \& McCullough, 2000), and (d) more positive appraisals of stressful events (Affleck \& Tennen, 1996). In a study by Gilman, Dooley, and Florell (2006) youth reporting high hope were found to be high on personal adjustment, global life satisfaction and self-reported grade point average. Ciarrochi, Davies and Heaven (2007) found hope to be the best predictor of grades. Valle, Huebner, \& Suldo (2006) provide support for consideration of hope as a key psychological strength in youth.

With regard to young adult assamese females Optimism, Hope and Happiness emerged as significant predictor of Psychological well-being. However, when the independent contributions of the three variables in the Psychological Well-Being of Assamese females were calculated, it was found that only Happiness emerged as the significant predictor of Psychological Well-Being with $53 \%$ of variance.

The significant contribution of Happiness towards Psychological Well-Being among the young adult Assamese females is acceptable as the status of women in the North East seems to be comparatively better than women in the rest of India, both in the tribal as well as the non-tribal societies of the region. They have greater levels of mobility, economic autonomy and active efforts in making their family than many women in other parts of India. Regarding the percentage of female in non-agricultural activities Assam is above the all India percentage of 2.89. The Northeast states do not bear the direct suppression of the women and they altogether enjoy more freedom as compared to western India (Gangmai, 2010). In the north east of India, women enjoy greater mobility and visibility than women of other communities in the country. Practices such as dowry and bride burning are not very prevalent in the region (Das, 2012). Education is a major catalyst in bringing about far-reaching changes in the status of women. The female literacy rate in Assam has increased considerably over the years. According to census 2011, it has risen from $56.03 \%$ in 2001 to $67.27 \%$ in 2011. Further, the gendergap in literacy (the number of female literates against the male literates) in Assam, which stood at $16 \%$ in 1997 , is less than the average national gender gap in literacy, which stands at $23 \%$. Findings of NFHS-II (a study conducted by the International Institute for Population Sciences, Mumbai, in collaboration with USAID and UNICEP in 1998-99) for the state of Assam were as follows: Only 5 percent of respondents are not involved in any household decision-making, 88 percent are involved in decisions about cooking, 65 percent in decisions about their own health care, 54 percent in decisions about purchases of jewellery and other such items, and 45 percent in decisions about going to stay with parents or siblings. Therefore the basic needs (Davidson \& Demir, 2013) and social relationships (Brodaty, Brodaty, Caunt and Franklin, 2013). Hence, happiness emerged as the strongest predictors of well-being among females.

In the case of Assamese males as already seen, hope emerged as the significant predictor of Psychological Well-Being. This could mostly be due to the reason mentioned above. Thus, the awareness of responsibility tinged with hope makes male feel more well and empowerment of women in terms of happiness makes women more well. Happiness comes only after the benefits of hope have been achieved. Therefore hope contributes more to psychological well-being in males, whereas happiness contributes more to psychological 
well-being in females. While being offered equal opportunities, gender differences exist in every aspect of health (Crose, Nicholas, Gobble \& Frank, 1992). In a Taiwanese study, Lu (2000) discovered gender differences while examining conjugal congruence on role experiences and subjective well-being. Stephens, Dulberg, \& Joubert, (1999) found gender differences in a study examining mental health in the Canadian population.

Persusal of table 3 shows that there existed significant difference between young adult males and females with respect to Psychological Well-Being. The comparison of both the groups show that females are higher in Psychological Well-Being as compared to males. In the same way, females were significantly happier than males because of the reasons discussed above. Even though the areas of males and females are evidently different in the state of Assam, the level of Optimism and Hope is almost the same in their respective fields. In a post-feminist context this incorporates the idea of an "equal opportunities" society; yet social stereotypes still remain (; Eagly, 1987; Turner \& Sterk, 1994).

Women enjoy adequate amount of decision making in the household (NFHS-II, 1998-99) and do not face gender biases as is seen in the rest of India. The results of the present study are in line with a study by, Roothman, Kirsten, \& Wissing (2003) on gender differences in aspects of Psychological Well-Being. It was found that women scored higher than men on the expression of affect and religious well-being. Women adopting a traditional definition of their gender role would be expected to be driven by a need to be nurturing and express emotional intimacy (Watkins \& Whaley, 2000), whereas men would retain a need for independence and a suppressed expression of emotion (Good, Sherrod, \& Dillon, 2000) in the riot-hit region. The results of the current study which show that women are significantly happier than men in Assam is in line of the results of regression analysis of the study where happiness emerged as a significant predictor of well-being among females. Same reasons which have been put forth for the explanation of significant contribution of happiness in well-being of females and significant contribution of hope in well-being of males can be taken here also that is, men are more likely to hope for advancing their careers and earning livelihood, while women do not feel the pressure to do so and enjoy adequate independence in their own sphere. Moreover, women of Assam perhaps do not face much abuse, which is also a source of happiness for them.

\section{References}

[1]. Adelabu, D. H. (2008). Future Time Perspective, Hope, and Ethnic Identity Among African American Adolescents. Urban Education, 43, 347-360.

[2]. Affleck, G., \&Tennen, H. (1996). Construing benefits from adversity: Adaptational significance and dispositional underpinning. Journal of Personality, 64, 899-922.

[3]. Altson, J. P. \& Dudely, C. J.(1987). Age, occupation and life satisfaction. Gerontologist, 13, 58.

[4]. Argyle, M., Martin, M. \&Cossland, J. (1989). Happiness as function of personality and social encounters: An international perspective, North Holland: Elsevier, 189-203.

[5]. Baker, L. A. (2005). Productive activities and subjective well-being. Journal of Social Indicators Research.

[6]. Brodaty, N. E., Brodaty, H., Caunt, B. S., \& Franklin, J. (2013). Exploring the Causes of Subjective Well-Being: A Content Analysis of Peoples' Recipes for Long-Term Happiness. Journal of Happiness Studies, 14, 475-499.

[7]. Calabia, A. (2000). Healthy Mind, Healthy Heart. Psychology Today (118). Retrieved April 13, 2007, from http://www.psychologytoday.com/articles/pto-20001101-000023.html

[8]. Ciarrochi, J., Heaven, C. L. \& Davies, F. (2007). The impact of hope, self-esteem, and attributional style on adolescents' school grades and emotional well-being: A longitudinal study. Journal of Research in Personality, 41, 1161-1178.

[9]. Crose, R., Nicholas, D. R., Gobble, D. C., \& Frank, B. (1992). Gender and wellness: A multidimensional systems model for counseling. Journal of Counseling and Development, 71, 149-156.

[10]. Das, J. (2012). Women's Human Rights in North- East India. Journal of Humanities and Social Science, 3, $34-37$.

[11]. Davidson, I. \&Demir, M. (2013). Toward a Better Understanding of the Relationship Between Friendship and Happiness: Perceived Responses to Capitalization Attempts, Feelings of Mattering, and Satisfaction of Basic Psychological Needs in SameSex Best Friendships as Predictors of Happiness. Journal of Happiness Studies, 12, 525-550.

[12]. Diener, E. (1984, ). Subjective well-being .Psychological Bulletin. 95, 542-575.

[13]. Diener, E. (2000). Subjective well-being: The science of happiness, and a proposal for national index. American Psychologist, 55, 34-43.

[14]. Diener, E., \& Diener, C. (1996). Most people are happy. Psychological Science, 7, 181-185.

[15]. Diener, E., \& Suh, E. (1997). Measuring quality of life: Economic, social, and subjective indicators. Social Indicators Research, 40, 189-216.

[16]. Eagly, A. H. (1987). Sex differences in social behaviour: A social-role interpretation. Hillsdale, New Jersey: LEA Publishers.

[17]. Freud, S. (1961). Civilization and its Discontents (J. Strachey, Trans.). New York: W. W. Norton. (Original work published 1930).

[18]. Gangmai, E. (2010). Position of Women in North East India. Retrieved December 26, 2013, from https://www.academia.edu/

[19]. Gilman, R., Dooley, J., \&Florell, D. (2006). A preliminary study of hope in adolescents. Journal of Social and Clinical Psychology, 25, 166-178.

[20]. Good, G.E., Sherrod, N., \& Dillon, M. (2000). Masculine gender role stressors and men's health. In R. Eisler\& M. Hersen (Eds.), Handbook of gender, culture, and health. Mahwah, NJ: Lawrence Erlbaum, 63-81.

[21]. Hills, P., \& Argyle, M. (2002). The Oxford Happiness Questionnaire: A compact scale for the measurement of psychological wellbeing. Personality and Individual Differences, 33, 1071-1082.

[22]. Irving, L. M., Snyder, C. R., \& Crowson, J. J., Jr. (1998). Hope and coping with cancer by college women. Journal of Personality, $22,195-214$

[23]. Kageyama, J. (2012). Happiness and Sex Difference in Life Expectancy. Journal of Happiness Studies, 13, $947-967$. 
[24]. Kesebir, P., \& Diener, E. (2008). In pursuit of happiness: Empirical answers to philosophical questions. Perspectives on Psychological Science, 3, 117-125.

[25]. Kitchener, B.A. \& Jorm, A.F. (2002). Mental Health First Aid Manual. Canberra: Centre for Mental Health Research

[26]. Lazarus, R. S., \&Folkman, S. (1984). Stress, Appraisal and Coping. New York: Springer.

[27]. Lu, L. ( 2000). Gender and Conjugal Differences in Happiness. The Journal of Social Psychology 140, 132-141.

[28]. Maruta, T., Colligan, R. C., Malinchoc, M., \&Offord, K. P. (2000). Optimists pessimists: survival rate among medical patients over a 30-year period. Division of Adult Psychiatry, Mayo Clinic Rochester, MN 55905, USA. Mayo Clin Proc., 75, 140-3.

[29]. McCullough, M.E., \& Snyder, C.R. (2000). Classical sources of human strength: Revisiting an old home and building a new one. Journal of Social and Clinical Psychology, 19, 1-10.

[30]. Moraitou, D., Kolovou, C., Papasozomenou, C., \&Paschoula C. (2006) Hope and Adaptation to Old Age: Their Relationship with Individual-Demographic Factors. Social Indicators Research, 76, 71-93.

[31]. NFHS-2, NATIONAL FAMILY HEALTH SURVEY. (1998-99). Maharashtra (Retrieved in May, 2013).

[32]. Nelson, M.A., Roberts, M. C., \& Snyder, C. R. (2010) EARLY ADOLESCENTS EXPOSED TO VIOLENCE: Hope and Vulnerability to Victimization. American Orthopsychiatric Association, 66, 3.

[33]. Páez, D., Sánchez, F. M. \&Seguel, A. M. (2012). Incremental Validity of Alexithymia, Emotional Coping and Humor Style on Happiness and Psychological Well-Being. Journal of Happiness Studies.

[34]. Park, N. (2004). Strengths of character and well-being. Journal of Social and Clinical Psychology, 23, 603-619.

[35]. Perneger, T. V., Hudelson, P. M. \& Patrick, A. (2004). Health and Happiness in Young Swiss Adults. Quality of Life Research, $13,171-178$

[36]. Kermani, Z., Khodapanahi, M. K., Heidari, M. (2012). Psychometric properties of Snyder's hope scale. Journal of Applied Psychology, 5, 7-23.

[37]. Reivich, K., \& Shatte', A. (2002). The resilience factor: Seven essential skills for overcoming life's inevitable obstacles, NY: BroadwayBooks.

[38]. Ryan, R. M. \&Deci, E. L. (2001). Department of Cllinical and Social Sciences in Psychology, University of Rochester, Rochester, NY.

[39]. Ryan, R. M., \& Huta, V. (2009). Wellness as healthy functioning or wellness as happiness: The importance of Eudaimonic Thinking. Journal of Positive Psychology, 4, 202-204.

[40]. Ryff, C. D. (1989). Happiness is everything, or is it? Explorations on the meaning of psychological well-being. Journal of Personality and Social Psychology, 57, 1069-1081

[41]. Ryff, C. D. (2005). Psychological well-being in adult life. Journal of Current Directions in Psychological Science, 4, 99-104

[42]. Ryff, C. D., \& Singer, B. H. (2008). Know thyself and become what you are: A eudaimonic approach to psychological well-being. Journal of Happiness Studies, 9, 13-39.

[43]. Scheier, M., \& Carver, C. (1985). Optimism, Coping, and Health: Assessment and Implications of Generalised Outcome Expectancies. Health Psychology, 4, 219-247.

[44]. Snyder, C.R. (2000). Handbook of Hope Theory, Measures and Applications. San Diego: Academic Press.

[45]. Snyder, C. R. (2002). Hope theory: Rainbows in the mind. Psychological Inquiry, 13, 249-275.

[46]. Snyder, C. R., Cheavens, J., \& Michael, S. T. (1999). Hoping. In C. R. Snyder (Ed.), Coping: The psychology of what works (pp. 205-231). New York: Oxford University Press.

[47]. Snyder, C. R., Harris, C., Anderson, J. R., Holleran, S. A., Irving, L. M., Sigmon, S. T., et al. (1991). The will and the ways: Development and validation of an individual-differences measure of hope. Journal of Personality and Social Psychology, 60, 570585 .

[48]. Snyder, C. R., Hoza, B., Pelham, W. E., Rapoff, M., Ware, L., \& Danovsky, M., et al. (1997). The development and validation of the childrens' hope scale. Journal of Pediatric Psychology, 22, 399-421.

[49]. Snyder, C. R., Lapointe, A. B., Crowson, J. J., Jr., \& Early, S. (1998). Preferences of high-and low-hope people for self referential feedback. Cognition and Emotion, 12, 807-823.

[50]. Snyder, C. R., \& Lopez, S. J. (2007). Positive psychology: The scientific and practical explorations of human strengths. Thousand Oaks, CA: Sage.

[51]. Snyder, C.R., \& McCullough, M. (2000). A positive psychology field of dreams: "If you build it, they will come..." Journal of Social and Clinical Psychology, 19, 151-160.

[52]. Snyder, C. R., Rand, K. L., \& Sigmon, D. R. (2002). Hope theory: A member of the positive psychology family. In C. R. Snyder \& S. J. Lopez (Eds.), Handbook of positive psychology, NY: Oxford University Press, 257-276.

[53]. Snyder, C. R., Simpson, S. C., Ybasco, F. C., Borders, T. F., Babyak, M. A., \& Higgins, R. L. (1996). Development and Validation of the State Hope Scale. Journal of Personality and Social Psychology, 70, 321-335.

[54]. Stephens, T., Dulberg, C. \&Joubert, N. (1999). Mental health of the Canadian population: a comprehensive analysis. Chronic Dis Can., 20, 118-26.

[55]. Turner, L. H. \& Sterk, H. M. (1994). Differences that make a difference. Connecticut: Bergin \& Garvey Publishers

[56]. Thompson, R.J., Jr., Gustafson, K.E., Hamlett, K.W., \& Spock, A. (1992). Stress, coping, and family functioning in the psychological adjustment of mothers of children with cystic fibrosis. Journal of Pediatric Psychology, 17, 573-585.

[57]. Valle, M. F., Huebner, E. S., \&Suldo, S. M. (2006). An analysis of hope as a psychological strength. Journal of School Psychology, 44, 393-406.

[58]. Vitterso, J. (2004). Subjective well-being versus self-actualization: using the flow simplex to promote a conceptual, clarification of subjective quality. Social Indicators Research, 65, 299-331.

[59]. Wang, M. \& Wong, M. C. (2013). Happiness and Leisure Across Countries: Evidence from International Survey Data. Journal of happiness Studies.

[60]. Waterman, A. S. (1993). Two conceptions of happiness: Contrasts of personal expressiveness (eudaimonia) and hedonic enjoyment. Journal of Personality and Social Psychology, 64, 678-691.

[61]. Watkins, P. L., \& Whaley, D. E. (2000). Gender role stressors and women's health. In R. M. Eisler, \& M. Hersen (Eds.), Handbook of gender, culture, and health, NJ: Lawrence Erlbaum, 43-62.

[62]. Wellner, A. S., \& Adox, D. (2000). Happy Days. Psychology Today, 33, 32-37. Retrieved December 20, 2013, from http://www.psychologytoday.com/articles/200005/happy-days 